\title{
Design of Any Ratio Methanol / Gasoline Dual-fuel Controller CHEN Xiang-kui ${ }^{1, a}$, ZHANG Cheng $^{2, b}$
}

\author{
${ }^{1}$ Academy of Information Technology, Luoyang Normal University,Luoyang,471022,China \\ ${ }^{2}$ Net and Educational Technology Center, Luoyang Normal University,Luoyang,471022,China \\ a email:hdchen97@163.com, ${ }^{\mathrm{b} e m a i l: 10471169 @ q q . c o m}$
}

Key words: Methanol gasoline; Fuel injection quantity; PWM

\begin{abstract}
This design of dual fuel controller is out of consideration to start the engine by using methanol gasoline of different proportioning since the calorific value of methanol is lower than that of gasoline. Adjusting the low- level width of injection pulse control signal from ECU and increasing the fuel injection quantity based on the blending ratio of methanol and gasoline can make the combustion heat produced by methanol gasoline reach that produced by burning gasoline, starting the engine successfully. The controller uses remote control to adjust the fuel injection quantity and display the pulse width correcting information. The installation of the controller does not prevent vehicles from using gasoline as the fuel. The controller, convenient in installation and energy saving, is proved through experiments to be very efficient.
\end{abstract}

\section{Introduction}

Energy crisis is universal and at the same time gas pollution produced during the process of burning gasoline has become the chief cause of smog and PM2.5. The comparison of gasoline and methanol in table 1 shows that the complete combustion of methanol needs less air than that of gasoline and that the heating value of methanol and air is equal to that of gasoline. With a high octane number, methanol as a fuel for vehicles is characterized by low cost and anti-detonation. Studies show that gas emission from methanol gasoline decreases sharply. Methanol, simple in composition, low in price and environment friendly, has been recognized and widely applied as a substitute for energy. [1-3]

\begin{tabular}{|c|c|c|c|}
\hline & molecular formula & calorific & octane \\
\hline methanol & $\mathrm{CH}_{3} \mathrm{OH}$ & 19.96 & 112 \\
\hline gasoline & $\mathrm{C}_{4} \sim \mathrm{C}_{14}$ & 43.66 & $84 \sim 96$ \\
\hline
\end{tabular}

The oil injection and ignition system in engine is designed originally with gasoline as the fuel. Therefore, in order to start the engine with methanol the fuel-injection quantity must be adjusted. Since the oil controlling signal is sent by ECU, the design and instillation of methanol controller is highly unnecessary.

Han Xiao xia and Zhang Qing shun[4] designed Dual Fuel Controller based on ARM, collecting the parameters of different parts of the engine and solving the problem of ignition with methanol gasoline. Yet the said controller is possible only with certain ratio of methanol and gasoline. Any addition of gasoline or methanol will change the blending ratio, yet the controller will continue to adjust the oil injection based on the fixed correction. So more gasoline will lead to waste of fuel and more methanol means failure in ignition. To adapt to the new proportion of the two fuel, the controller must again adjust the pulse width correction of oil injection. That means a new programming, a specific programmer and a highly skillful staff. Meanwhile the Dual Fuel Controller designed by Han and Zhang employs ARM controller, therefore, it is costly and unsuitable for application. 


\section{Theory Behind the Design}

Calorific value refers to the amount of heat released from the complete burning of the fuel. It directly makes a difference in the performance of the engine, therefore, it is a major index in appraising a vehicle. table Two, comparing the calorific value of differently-ratioed methanol gasoline and that of 93\#gasoline, [5]shows that calorific value of methanol gasoline decreases with the increasing ratio of methanol.

Table 2 calorific value of different ratio methanol/gasoline

\begin{tabular}{lccccc}
\hline methanol/gasoline & $93 \#$ & M15 & M25 & M85 & M100 \\
\hline calorific $\left(\mathrm{MJ} \cdot \mathrm{kg}^{-1}\right)$ & 43.66 & 39.90 & 38.46 & 22.20 & 19.96 \\
\hline
\end{tabular}

At present most of the engine injection system is designed with gasoline as the fuel, that is, the heat produced in the burning of gasoline within unit ignition interval should satisfy the amount of heat needed to start the engine. Methanol gasoline has got a lower calorific value, so as long as the injection quantity within unit ignition time is elevated and the heat from the burning of methanol gasoline reaches the amount needed for the ignition, the engine can be started. the engine can be started with differently proportioned methanol gasoline by correcting the injection quantity based of the different ratio of the two fuel.

The engine nozzle is an electromagnetic switch, one terminal of which is linked to the power supply of 12 Volt and the other is the injection signal connected with the ECU. when the signal is of low level, the nozzle starts injecting; and the injection quantity changes with the adjustment of the pulse width. When the signal is changed into high level, the injection stops [6]. Therefore, adjusting the lasting time of the pulse width of the low level can realize the purpose of starting engine with methanol gasoline of random ratio.

\section{The Design Perse}

The oil controlling signal, directly connected with the nozzle terminal, is sent by ECU according to the condition of the vehicle in motion. In order to correct the injection quantity without changing the original ECU, the original nozzle circuit needs to be cut off and the injection controlling signal sent by ECU linked to methanol controller, then the low level pulse width will be adjusted corresponding to the different ratio between methanol and gasoline. The thus adjusted controlling signal will be sent to the engine nozzle, as is illustrated in Figure 1.

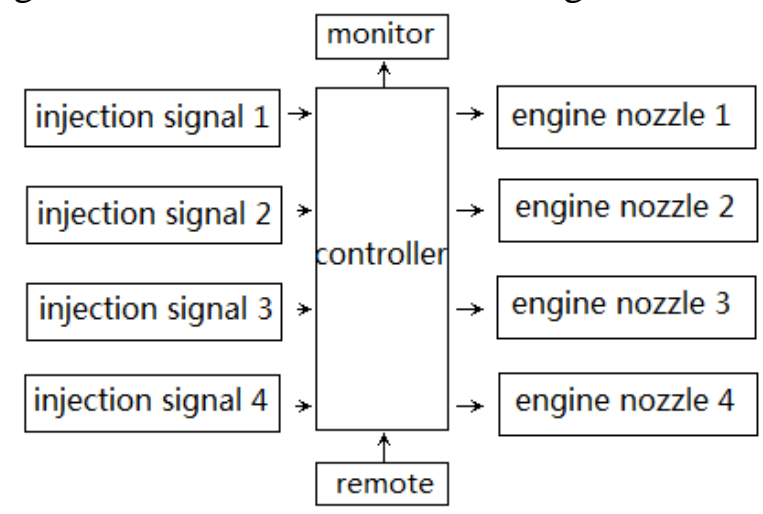

Fig.1 controller structure

To render it easy to install and operate, a remote control is perfect for adjusting injection quantity according to different ratio of methanol and gasoline. The addition of monitor can help to observe the chosen injection gears plainly. To lower the cost, the main processor uses single chip microcomputer.

\section{Hardware Designing}

The controller employs STC12C2052 single chip microcomputer, which consists of non-volatile 
EEPROM memory and four PWM pulse width modulator. To avoid repeated modulation at each time of ignition, EEPROM can be used to store the correction value of the previous injection quantity, this data will remain there even after the vehicle is shut down. the four PWM can modulate the pulse width of four injection controlling signal. The related circuit is shown in Figure 2.

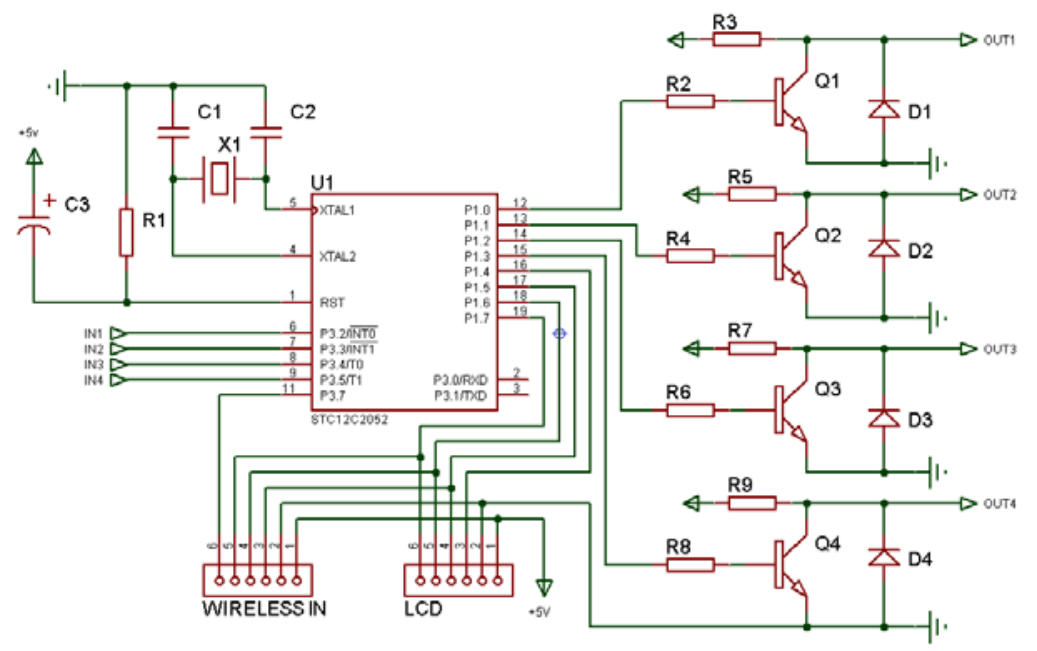

Fig. 2 controller circuit

P3.2-p3.5 terminal is used to detect and receive the injection controlling signal sent by ECU. The correction value sent by the remote control modulates the PWM pulse width and the modulated injection signal then is sent to the engine nozzle through P1.0-P3.0.

The controller has got 12 gears, modulating the PWM pulse width corresponding to different ratio between gasoline and methanol. The Zero gear does not modulate pulse width, instead, it directly sends the injection signal launched by ECU to the nozzle, making sure that the engine can be started even without changing the injection pulse width when the vehicle uses gasoline as the fuel.

To improve the drive capacity of the controller, Darlington transistor is utilized at the output terminal. Called also as compound transistor, Darlington transistor combines two transistors to form an equivalent transistor characterized by a high input impedance, a low output impedance and stone load capacity.

The nozzle is a highly sophisticated electromagnetic switch. When the current goes through, the coil will produce induced electromotive force at the both ends. When the current disappears, the induced electromotive force will generate reverse voltage on the components in the circuit. When the reverse voltage surpasses the reverse breakdown voltage of the components, the transistor will be damaged. Therefore, at the terminal freewheel diodes are connected in parallel at the both ends of the nozzle. in this way, when the current going through the coil disappears, the induced electromotive force produced by the coil is consumed in the return circuit formed by the diode and the coil, guaranteeing the stability of the components in the circuit.

P3.0 and P3.1 are connected with the serial port of the computer to to realize serial communication and program download. The serial of the Single chip computer is TTL level, while the serial of PC is RS-232 level, thus the two levels are not compatible. To reduce the cost as well as the volume of the controller, a module changing from RS-132 to TTL should be linked in the process of programming, while the circuit board of the controller preserves only the programming interface.

\section{Software Programming}

The process of the software of the Dual-fuel controller is as follows:

After it is initialized, the CPU loads from EEPROM the correction value of the latest modulation, computes the four injection controlling signals sent by ECU, confirms the pulse width data and finally outputs it to the nozzle after the modulation. When CPU finds new correction value input by 
the remote control, it will store it into EEPROM, modulate based on the new data the four injection controlling signals and then output it to the nozzle. After that the present correction information will be displayed through the indicator.

\section{Conclusion}

This dual-fuel controller is designed out of the purpose of starting the engine with methanol and gasoline of different ration, for methanol, as a constitute fuel, has a low heating value. The experiments on the waveform before and after the signal modulations done with the signal generator and oscilloscope show that the controller is efficient and stable as well. Its test run on taxis shows that randomly-proportioned methanol gasoline can successfully ignite the engine with the help of the remote control and it runs smoothly. Compared with other controllers, the one under discussion, with more gears, can lower the cost of consumption by modulating the injection quantity to the minimum. Moreover, the installment of the controller does not prevent the auto from using gasoline as the fuel. Convenient in installation, low in cost and friendly to environment, the controller at present has been widely promoted and applied.

\section{References}

[1]Wang Xiang Guo Yongjun etc. Comparsion of Methanol, Gasoline and Methanol- gasoline as Motor fuel [J].Chemical Industry Times, 2005,3:46-49.

[2]YIN Hang, HAO Chun-xiao etc. Emission Characteristics of Vehicles Fueled with Different Proportion Mixtures of Methanol-Gasoline Fuel[J]. Research of Environmental Sciences, 2011,8:917-924.

[3]Wu Yuqi, Feng Xiangfa.Methanol Fuel: the Most Competitive Alternative Energy[J]. China Foreign Energy,

[4]HAN Xiao xia, ZHANG Qingshun.Design of ARM-based methanol/gasoline dual-fuel controller [J]. Journal of Hebei University,2013,4:424-428.

[5]XUE Li-li, LIU Qiong-qiong etc,.Research on the Heating Value of Methanol Gasoline [J].Internal Combustion Engines, 2011,5:33-36.

[6]YAN Wen-bing, JIANG Shao-zhong.Converting car in use into methanol/gasoline flexible one [J].Journal of Tianjin University of Technology and Education, 2010,20(1):24-26. 